\title{
PENGUJIAN NITROGEN TOTAL, KANDUNGAN AIR DAN CEMARAN LOGAM TIMBAL PADA PUPUK ANORGANIK NITROGEN PHOSPOR KALIUM (NPK) PADAT
}

\author{
${ }^{1}$ B. Wiyantoko, ${ }^{2}$ P. Kurniawati, ${ }^{3}$ T.E. Purbaningtias \\ Prodi DIII Analis Kimia Fakultas MIPA \\ Universitas Islam Indonesia \\ Yogyakarta, Indonesia \\ e-mail: bayuwiyantoko@uii.ac.id
}

\begin{abstract}
Abstrak
Telah dilakukan pengujian kualitas pupuk anorganik NPK padat meliputi kandungan nitrogen total, kandungan air dan cemaran logam timbal $(\mathrm{Pb})$. Pengujian kualitas pupuk NPK padat dan standar mutu hasi pengujian berdasarkan metode standar SNI 2803 tahun 2010. Pengujian nitrogen total menggunakan metode Kjledahl, kandungan air menggunakan metode Aufhauser dan cemaran logam timbal secara spektrofotometri serapan atom (AAS). Pengujian nitrogen dengan metode Kjledahl meliputi tiga tahapan yaitu destruksi, destilasi dan titrasi. Kadar nitrogen total yang diperoleh sebesar $10.50 \%$ dengan batas minimal yaitu $8 \%$. Pengujian kandungan air diperoleh hasil yaitu 2,67\% yang masih dibawah batas maksimal sebesar 3\%. Untuk kadar cemaran logam berat $\mathrm{Pb}$ diperoleh sebesar $16,03 \mathrm{mg} / \mathrm{kg}$ yang memenuhi syarat mutu yaitu maksimal $500 \mathrm{mg} / \mathrm{kg}$.
\end{abstract}

Kata kunci: timbal, metode Aufhauser, metode Kjeldahl, pupuk NPK padat,

\section{Abstract}

The quality of solid inorganic fertilizer NPK including total nitrogen content, moisture content and metal contamination of lead have been done. The determination of NPK fertilizer and quality standards results based on the standard method SNI 2803:2010. The total nitrogen content using Kjledahl method, the water content using the Aufhauser method and lead metal contamination by atomic absorption spectrophotometry (AAS).Quantitative determination of nitrogen content using Kjledahl method includes three stages namely digestion, distillation and titration. The total nitrogen content obtained $10.50 \%$ with a minimum limit of $8 \%$. The water content resulted $2.67 \%$ which is below the maximum limit of $3 \%$. For the contamination levels of heavy metals $\mathrm{Pb}$ obtained around $16.03 \mathrm{mg} / \mathrm{kg}$ which meet the quality requirements for a maximum of $500 \mathrm{mg} / \mathrm{kg}$.

Keywords: Lead, Aufhauser method, Kjeldahl method, solid NPK fertilizers

\section{PENDAHULUAN}

Pupuk merupakan suatu bahan yang ditambahkan ke dalam tanah untuk menyediakan unsur hara yang penting bagi pertumbuhan tanaman.Pupuk juga dapat didefinisikan sebagai suatu material yang ditambahkan pada media tanam atau tanaman untuk mencukupi kebutuhan hara yang diperlukan tanaman sehingga mampu berproduksi dengan baik (Rinsema, 1993).

Pupuk dapat dibagi menjadi 2 jenis yaitu pupuk organik dan pupuk anorganik.Pupuk organik adalah jenis pupuk yang tersusun atas materi makhluk hidup seperti pelapukan sisa-sisa tanaman, hewan dan manusia, sedangkan pupuk organik dapat berbentuk padat atau cair yang digunakan untuk memperbaiki sifat fisika, kimia, dan biologi tanah.Pupuk organik mengandung banyak bahan-bahan organik daripada unsur haranya.Sumber pupuk organik dapat berupa kompos, pupuk hijau, pupuk kandang, sisa panen (bagas tebu, brangkasan, jerami, tongkol jagung, dan sabut kelapa, serta limbah ternak). Untuk pupuk anorganik adalah pupuk yang dibuat 
oleh pabrik-pabrik pupuk dengan meramu bahan-bahan kimia anorganik berkadar hara tinggi seperti urea, NPK, dan lain-lain (Lingga \& Marsono, 2000).

Pupuk NPK adalah jenis pupuk buatan yang berbentuk cair atau padat yang memiliki kandungan unsur hara nitrogen, fosfor dan kalium.Pupuk NPK merupakan salah satu jenis pupuk anorganik yang paling umum digunakan oleh masyarakat dalam bidang pertanian maupun perkebunan. Kandungan unsur hara pada pupuk NPK adalah nitrogen $15 \%$ dalam bentuk $\mathrm{NH}_{3}$, fosfor $15 \%$ dalam bentuk $\mathrm{P}_{2} \mathrm{O}_{5}$, dan kalium $15 \%$ dalam bentuk $\mathrm{K}_{2} \mathrm{O}$. Sifat nitrogen (pembawa nitrogen) terutama dalam bentuk amoniak menambah sifat keasaman tanah yang dapat menunjang pertumbuhan tanaman (Hardjowigeno, 2003)

Secara umum parameter kualitas pupuk NPK padat seperti kandungan nitrogen, fosfor, kadar air, cemaran logam $(\mathrm{Pb}, \mathrm{Cd}, \mathrm{Hg})$ dan arsen (As). Nitrogen merupakan unsur hara utama bagi tumbuhan yang pada umumnya sangat diperlukan untuk pembentukan atau pertumbuhan bagian-bagian tanaman seperti daun, batang, dan akar tetapi jika jumlahnya terlalu banyak dapat menghambat pembungaan dan pembuahan pada tanaman.Kadar air merupakan persentase banyaknya air yang terkandung dalam pupuk yang dinyatakan dalam satuan persen.Logam $\mathrm{Pb}$ adalah salah satu cemaran logam yang ada dalam pupuk NPK padat.Dari beberapa unsur ini memiliki dampak yang berbeda-beda yang dapat mempengaruhi pertumbuhan dan perkembangan tanaman dan bahkan dapat mempengaruhi kesehatan manusia.

Nitrogen juga memiliki peranan yaitu merangsang pertumbuhan tanaman secara keseluruhan, khususnya batang, cabang dan daun (Lindawati, Izhar, \& Syafira, 2000) Nitrogen penting dalam hal pembentukan hijau daun yang berguna sekali dalam proses fotosintesis. Unsur fosfor merupakan bahan pembentuk sel inti, selain itu mempunyai peranan penting bagi pembelahan sel meristematik. Pengujian kandungan nitrogen total dalam pupuk NPK dilakukan menggunakan metode Kjeldahl yang terdiri dari proses destruksi, destilasi dan titrasi. Untuk pengujian kadar air menggunakan metode Aufhauser, sedangkan cemaran logam $\mathrm{Pb}$ dianalisis menggunakan spektrofotometer serapan atom (SSA). Pengujian logam $\mathrm{Pb}$ menggunakan AAS karena pengukurannya langsung terhadap contoh atau spesifik pada logam $\mathrm{Pb}$, mempunyai kepekaan yang tinggi, pelaksanaannya relatif sederhana, akurat, dan dapat diaplikasikan pada banyak unsur.

Penelitian ini bertujuan untuk menguji parameter penyusun pupuk NPK padat khususnya kandungan nitrogen, kadar air dan cemaran logam $\mathrm{Pb}$. Pengujiian ini sangat penting dilakukan untuk mengetahui kualitas pupuk NPK padat yang dijual di pasaran agar memenuhi standar yang telah ditetapkan.Parameter yang melebihi standar yang telah ditetapkan akan menurunkan kualitas produk selain juga berpengaruh terhadap media tanah. Unsur nitrogen yang berlebih pada pupuk akan menghambat pertumbuhan bunga dan pembuahan, pertumbuhan melambat serta daun menguning (klorosis). Kadar air yang tinggi akan mempengaruhi tekstur pupuk NPK sedangkan kadar $\mathrm{Pb}$ yang melebihi standar akan memberikan pengaruh toksik pada proses fotosintesis dan pertumbuhan tanaman. Pengujian pada penelitian ini dilakukan berdasarkan metode standar SNI 2803:2010 tentang pupuk NPK padat yang juga digunakan sebagai acuan standar hasil pengujian.

\section{METODE \\ Alat dan Bahan}

Alat-alat yang dipakai dalam penelitian ini meliputi peralatan gelas, seperangkat alat uji Kjeldahl, magnetic stirrer, seperangkat alat destilasi Aufhauser, penangas listrik dan spektrofotometer serapan atom (AAS) Perkin Elmer PinAcle 900T.

Bahan-bahan yang digunakan pada penelitian ini antara lain pupuk anorganik NPK padat, larutan asam sulfat salisilat, $\mathrm{H}_{2} \mathrm{SO}_{4}$ pekat, $\mathrm{HCl}$ pekat, $\mathrm{HNO}_{3}$ pekat, larutan asam borat $1 \%, \mathrm{Na}_{2} \mathrm{~S}_{2} \mathrm{O}_{3} .5 \mathrm{H}_{2} \mathrm{O}$, larutan $\mathrm{H}_{2} \mathrm{SO}_{4} 0.05 \mathrm{~N}$, indikator Conway, larutan $\mathrm{NaOH} 40 \%$, akuabides, ksilena dan larutan induk Pb 1000 mg/L. Sampel pupuk 
NPK padat yang digunakan hanya satu jenis dari merk tertentu yang banyak dijual dan digunakan oleh masyarakat.

\section{Penentuan Nitrogen Total}

Pupuk NPK padat dihaluskan terlebih dahulu kemudian ditimbang sebanyak 0,5 g. Sampel pupuk NPK dimasukkan ke dalam labu Kjeldahl ditambahkan $25 \mathrm{~mL}$ larutan asam sulfatsalisilat dan dibiarkan semalam. Esok hari ditambahkan 4 g $\mathrm{Na}_{2} \mathrm{~S}_{2} \mathrm{O}_{3} .5 \mathrm{H}_{2} \mathrm{O}$ dan dipanaskan pada suhu rendah hingga gelembung habis. Temperatur dinaikkan secara bertahap hingga maksimum $300^{\circ} \mathrm{C}$ dan dibiarkan kembali ke temperatur ruang. Bagan proses destruksi sampel pupuk seperti ditunjukkan pada Gambar 1.

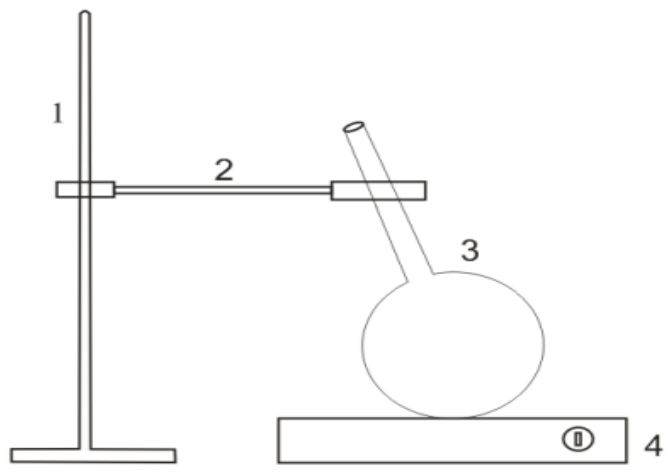

Keterangan: 1 dan 2 = Statif klem

$$
3 \text { = labu Kjeldahl }
$$$$
4 \text { = pemanas }
$$

Gambar 1.Rangkaian proses destruksi

Ekstrak dipindahkan ke dalam labu takar $500 \mathrm{~mL}$ dan diencerkan dengan air suling. Sampel dipipet sebanyak $25 \mathrm{~mL}$, dimasukkan ke dalam labu alas bulat, ditambahkan $150 \mathrm{~mL}$ akuabides, $10 \mathrm{~mL}$ larutan $\mathrm{NaOH} 40 \%$ dan batu didih. Proses penyulingan berlangsung hingga destilat mencapai $75 \mathrm{~mL}$ yang ditampung dalam wadah berisi asam borat $1 \%$ dan indikator Conway. Bagan proses destilasi pada pengujian nitrogen dengan metode Kjeldahl ditunjukkan Gambar 2.

$C(\%)=\frac{(\mathrm{V} 1-\mathrm{V} 2) \times \mathrm{N} \times 14,008 \times \mathrm{p} \times 100 \times \mathrm{fk}}{W}$

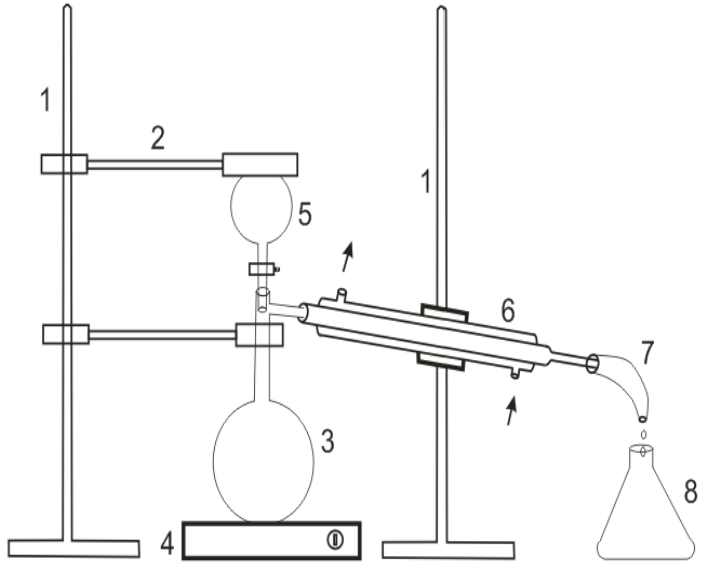

Keterangan: 1 dan 2 = statif klem

$3=$ labu Kjeldahl

$4=$ pemanas

$5=$ labu alas bulat

6 = kondensor liebig

7 = pipa bengkok

8 = erlenmeyer

Gambar 2. Rangkaian proses destilasi

Destilat hasil proses penyulingan dititrasi dengan larutan $\mathrm{H}_{2} \mathrm{SO}_{4}$ 0,5 N. Prosedur yang serupa dilaksanakan terhadap blanko. Bagan rangkaian alat proses titrasi ditunjukkan pada Gambar 3.

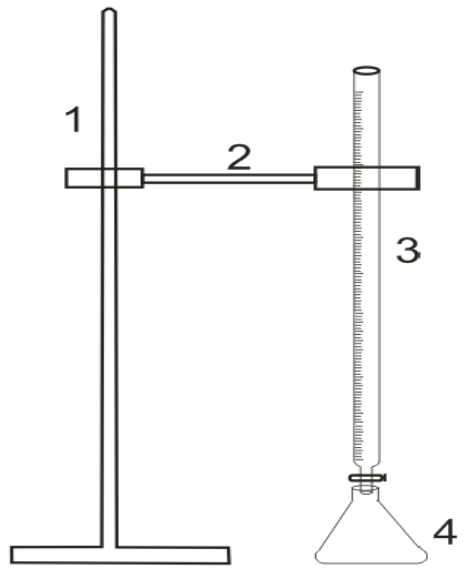

Keterangan: 1 dan 2 = statif klem

$$
\begin{aligned}
& 3=\text { buret } \\
& 4=\text { erlenmeyer }
\end{aligned}
$$

Gambar 3. Rangkaian proses titrasi

Volume titrasi sampel maupun blanko digunakan untuk menghitung kandungan nitrogen total pada sampel pupuk NPK padat. Untuk mengetahui kandungan nitrogen total digunakan rumus seperti tertera pada persamaan 1 . 
Keterangan:

C = kadar nitrogen total

$\mathrm{V}_{1} \quad=$ volume titrasi sampel

$\mathrm{V}_{2} \quad=$ volume titrasi blangko

$\mathrm{N}=$ normalitas $\mathrm{H} 2 \mathrm{SO} 4$

$14,008=$ berat atom nitrogen

$\mathrm{W}=$ berat sampel

$\mathrm{p} \quad=$ faktor pengenceran

Fk = faktor koreksi kadar air

\section{Penentuan Kadar Air}

Sampel pupuk NPK sebanyak $15 \mathrm{~g}$ dimasukkan ke dalam labu didih $100 \mathrm{~mL}$ ditambahkan $30 \mathrm{~mL}$ ksilena dan batu didih. Setting alat Aufhauser (Gambar 4) kemudian dipanaskan selama $1 \mathrm{jam}$. Alat pendingin dibilas dengan ksilena setelah proses pemanasan selesai. Jumlah volume air pada alat ditentukan dengan seksama.

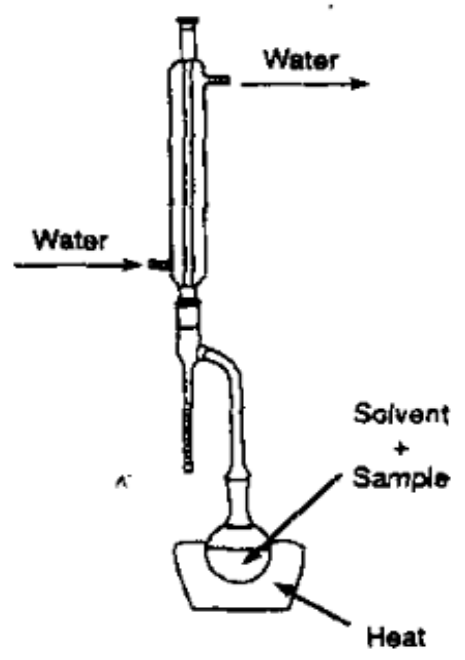

Gambar 4. Rangkaian alat metode Aufhauser(Nielsen, 2003)

\section{Penentuan Kandungan $\mathbf{P b}$}

Sampel pupuk NPK ditambahkan 30 $\mathrm{mL} \mathrm{HCl}$ pekat kemudian didestruksi selama 30 menit hingga sampel kering. Selanjutnya ditambahkan kembali $\mathrm{HCl}$ pekat dan dipanaskan kembali hingga larut semua. Larutan sampel dipindahkan dan diencerkan ke labu takar $100 \mathrm{~mL}$.

Larutan standar kerja $\mathrm{Pb}$ dibuat sebanyak $10 \mathrm{~mL}$ dengan konsentrasi $0,1,5$, 10, 15 dan $20 \mathrm{mg} / \mathrm{L}$. Larutan sampel dan standar kerja selanjutnya dianalisis menggunakan instrumentasi AAS yang telah dioptimasi.

\section{HASIL DAN PEMBAHASAN}

Pengujian pupuk anorganik NPK padat pada penelitian ini sangat penting dilakukan sebagai sebuah kontrol kualitas produk yang digunakan secara luas oleh konsumen. Jenis pupuk yang lazim digunakan yaitu pupuk organik dan pupuk anorganik yang keduanya memiliki fungsi sama yaitu menyediakan unsur hara yang penting untuk memperbaiki sifat fisik, kimia dan biologi tanah.

Pupuk organik yang selama ini digunakan masih belum mampu untuk memenuhi kebutuhan unsur hara essensial karena kandungannya yang jauh lebih rendah dari pupuk anorganik, meskipun ketersedian unsur hara lambat sehingga tidak mudah hilang.Ketersediaan unsur hara essensial seperti nitrogen, fosfor dan unsur lainnya yang rendah pada pupuk organik karena unsur-unsur tersebut dalam bentuk senyawa komplek organik protein atau senyawa asam humat atau lignin yang sulit terdekomposisi. Oleh karena itu pemakaian pupuk anorganik sangat penting bagi tanah untuk membantu ketersediaan unsur hara dengan jumlah yang sesuai agar tidak menghambat pertumbuhan tanaman.

Standar mutu hasil pengujian mengacu kepada SNI 2803:2010 seperti tertera pada Tabel 1.

\section{Penentuan Nitrogen Total}

Penentuan kandungan nitrogen dalam sampel pupuk anorganik NPK padat disebut sebagai nitrogen total karena yang ditentukan adalah unsur nitrogen secara keseluruhan yaitu nitrogen dalam bentuk ion nitrat $\left(\mathrm{NO}_{3}{ }^{-}\right)$, amonium $\left(\mathrm{NH}_{4}{ }^{+}\right)$dan $\mathrm{NH}_{3}$ yang dapat diserap oleh tanaman.

Sebagian besar nitrogen diserap dalam bentuk ion nitrat karena anion selalu berada didalam larutan tanah dan mudah terserap oleh akar.Oleh karena ion nitrat selalu berada didalam larutan tanah, maka ion nitrat lebih mudah tercuci oleh aliran tanah. Sebaliknya untuk ion amonium yang bermuatan positif terikat oleh koloid tanah. Ion amonium dapat dimanfaatkan oleh tanaman setelah melalui proses pertukaran kation. Oleh karena ion amonium bermuatan positif, maka ion ini tidak mudah hilang oleh proses pencucian. Penentuan nitrogen total dalam sampel pupuk anorganik dilakukan dengan metode Kjeldahl, yang terdiri dari tiga proses yaitu destruksi, destilasi dan titrasi (Novizan, 2002). Prinsip penentuan 
nitrogen total dengan metode Kjeldahl adalah nitrogen dalam contoh pupuk NPK padat dihidrolisis dengan asam sulfat membentuk senyawa amonium sulfat. Senyawa nitrat dengan asam salisilat membentuk nitrosalisilat kemudian direduksi dengan natrium tiosulfat membentuk senyawa amonium. Produk hasil destruksi yaitu senyawa amonium disuling dalam suasana alkali yang ditampung dengan asam borat. Destilat yang dihasilkan dititrasi dengan larutan asam sulfat sampai terjadi perubahan warna hijau menjadi merah muda.

Tabel 1. Spesifikasi Persyaratan Mutu dan Hasil Pengujian

\begin{tabular}{|c|c|c|c|c|c|}
\hline No & Jenis Uji & Satuan & Persyaratan & $\begin{array}{lr}\text { Batas } & \text { Toleransi } \\
\text { Minimal yang } & \text { yipersyaratkan }\end{array}$ & $\begin{array}{l}\text { Hasil } \\
\text { Pengujian }\end{array}$ \\
\hline 1 & Nitrogen total & $\%, b / b$ & & 8 & 10,50 \\
\hline 2 & $\begin{array}{l}\text { Fosfor total sebagai } \\
\mathrm{P}_{2} \mathrm{O}_{5}\end{array}$ & $\%, b / b$ & Sesuai formula & 8 & \\
\hline 3 & $\begin{array}{l}\text { Kalium sebagai } \\
\mathrm{K}_{2} \mathrm{O}\end{array}$ & $\%, b / b$ & $\begin{array}{l}\text { yang ada di } \\
\text { label }\end{array}$ & 8 & \\
\hline 4 & $\begin{array}{l}\text { Jumlah kadar } \mathrm{N} \text {, } \\
\mathrm{P}_{2} \mathrm{O}_{5}, \mathrm{~K}_{2} \mathrm{O}\end{array}$ & $\%, b / b$ & & 8 & \\
\hline $\begin{array}{l}5 \\
6\end{array}$ & $\begin{array}{l}\text { Kadar air } \\
\text { Cemaran logam }\end{array}$ & $\%, b / b$ & Maksimal 3 & & 2,67 \\
\hline- & Raksa $(\mathrm{Hg})$ & $\mathrm{mg} / \mathrm{kg}$ & Maksimal 10 & & \\
\hline - & Kadmium (Cd) & $\mathrm{mg} / \mathrm{kg}$ & Maksimal 100 & & \\
\hline- & Timbal $(\mathrm{Pb})$ & $\mathrm{mg} / \mathrm{kg}$ & Maksimal 500 & & 16,03 \\
\hline 7 & Arsen (As) & $\mathrm{mg} / \mathrm{kg}$ & Maksimal 100 & & \\
\hline
\end{tabular}

Proses pengujian nitrogen diawali dengan preparasi sampel pupuk anorganik NPK padat yang dihaluskan dengan mortar. Sampel pupuk perlu dihaluskan agar menghasilkan luas permukaan yang lebih besar sehingga mampu berinteraksi dengan reagen-reagen pereaksi lebih optimal. Sampel pupuk direaksikan dengan larutan asam sulfat-salisilat untuk menguraikan senyawa nitrogen menjadi amonium sulfat dan senyawa nitrat terurai menjadi nitrosalisilat oleh asam salisilat. Tahap destruksi sampel memiliki tujuan agar sampel pupuk tersebut mudah larut dan menghilangkan senyawa-senyawa yang tidak diperlukan dalam sampel.

Sampel hasil proses destruksi direaksikan dengan reagen natrium tiosulfat untuk mengkonversi senyawa nitrosalisilat menjadi amonium sulfat. Reaksi yang terjadi pada proses destruksi yaitu sebagai berikut: $\mathrm{N}$-Organik $(\mathrm{s})+\mathrm{H}_{2} \mathrm{SO}_{4(\mathrm{l})} \rightarrow\left(\mathrm{NH}_{4}\right)_{2} \mathrm{SO}_{4(\mathrm{aq})}+$

$$
\mathrm{H}_{2} \mathrm{O}_{(\mathrm{l})}+\mathrm{CO}_{2(\mathrm{~g})}+\mathrm{SO}_{2(\mathrm{~g})}
$$

Proses destruksi dilanjutkan dengan pemanasan pada temperatur rendah yaitu dibawah $300^{\circ} \mathrm{C}$ untuk menghindari lepasnya senyawa $\mathrm{NO}_{2}$ yang dapat mengakibatkan sebagian unsur nitrogen dalam sampel dapat turut menghilang. Proses destruksi dihentikan apabila warna larutan sampel menjadi jernih (tidak keruh) yang menandakan bahwa senyawa-senyawa yang ada didalam sampel telah terurai atau terdestruksi menjadi pertikel terlarut tanpa adanya partikel yang tersisa.

Proses destruksi yang dilakukan pada penelitian ini adalah jenis destruksi basah dengan menggunakan asam kuat sebagai oksidator yaitu asam sulfat. Proses destruksi berlangsung sempurna apabila dihasilkan produk berupa larutan jernih yang mengindikasikan semua komponen telah larut sempurna atau senyawa-senyawa organik telah mengalami perombakan secara sempurna. Parameter yang menjadi titik kritis saat proses destruksi adalah sifat matriks dan konstituen yang terkandung di dalam sampel pupuk. Komponen penyusun serta matriks sampel pupuk NPK padat yang heterogen membutuhkan kondisi reaksi yang spesifik seperti zat pengoksidasi kuat 
dan energi pemanasan yang tinggi untuk mendegradasi zat-zat-zat organic (Raimon, 1993).

Ekstrak yang diperoleh dari proses destruksi selanjutnya dilakukan proses penyulingan (destilasi). Prinsip destilasi adalah memisahkan cairan atau larutan berdasarkan perbedaan titik didih dimana semakin tinggi titik didihnya maka proses destilasi akan berjalan lebih cepat. Tujuan destilasi pada pengujian ini yaitu memecah amonium sulfat menjadi gas amonia $\left(\mathrm{NH}_{3}\right)$ dengan menambahkan $\mathrm{NaOH} 40 \%$ hingga kondisi reaksi tepat basa, lalu larutan dipanaskan.

Kristal $\mathrm{NaOH}$ apabila ditambahkan dengan akuades juga dapat menghasilkan panas, meski energinya tidak terlalu besar jika dibandingkan dengan pemanasan dari alat destilasi. Energi panas yang dihasilkan alat destilasi juga berasal dari reaksi antara $\mathrm{NaOH}$ dengan $\left(\mathrm{NH}_{4}\right)_{2} \mathrm{SO}_{4}$ yang merupakan reaksi eksotermis melepaskan sejumlah energi. Penambahan batu didih bertujuan agar pemanasan berlangsung merata dan meminimalisir terjadi letupan pada saat pemanasan.Larutan $\quad \mathrm{NaOH} \quad 40 \%$ ditambahkan secara berlebih saat proses destilasi untuk memberikan suasana basa agar unsur nitrogen yang dilepaskan secepatnya membentuk gas amonia. Reaksi yang terjadi pada selama proses destilasi berlangsung adalah sebagai berikut.

$$
\begin{gathered}
\left(\mathrm{NH}_{4}\right)_{2} \mathrm{SO}_{4(\mathrm{aq})}+2 \mathrm{NaOH}_{(\mathrm{aq})} \rightarrow \mathrm{Na}_{2} \mathrm{SO}_{4(\mathrm{~g})}+ \\
2 \mathrm{H}_{2(\mathrm{~g})}+2 \mathrm{NH}_{3(\mathrm{~g})} \\
2 \mathrm{NH}_{3(\mathrm{~g})}+2 \mathrm{H}_{3} \mathrm{BO}_{3(\mathrm{aq})} \rightarrow 2 \mathrm{NH}_{4} \mathrm{H}_{2} \mathrm{BO}_{3(\mathrm{aq})}
\end{gathered}
$$

Gas amonia yang dibebaskan akan dijerap dalam larutan asam borat $1 \%$ dalam volume yang berlebih. Agar gas amonia dapat dijerap secara maksimal, maka ujung pipa bengkok diusahakan tercelup sedalam mungkin dalam larutan asam borat yang telah ditambahkan dengan indikator Conway. Fungsi indikator Conway untuk mengetahui titik akhir gas amonia yang telah terjerap yang ditandai oleh perubahan warna larutan menjadi hijau kebiruan. Destilat yang diperoleh dihitung volume akhirnya untuk selanjutnya dititrasi menggunakan larutan $\mathrm{H}_{2} \mathrm{SO}_{4} \quad 0,05$ N.Titik akhir titrasi ditunjukkan oleh perubahan warna larutan sampel dari hijau kebiruan menjadi merah muda. Reaksi yang terjadi pada proses titrasi adalah sebagai berikut: $2 \mathrm{NH}_{4} \mathrm{H}_{2} \mathrm{BO}_{3(\mathrm{aq})}+\mathrm{H}_{2} \mathrm{SO}_{4(\mathrm{aq})} \rightarrow\left(\mathrm{NH}_{4}\right)_{2} \mathrm{SO}_{4}(\mathrm{aq})+$

$$
\mathrm{H}_{3} \mathrm{BO}_{3(\mathrm{aq})}
$$

Dari pengujian yang telah dilakukan diperoleh volume titrasi sampel secara duplo masing-masing yaitu $4 \mathrm{~mL}$ dan $3.5 \mathrm{~mL}$ sehingga didapat volume rata-rata adalah $3,75 \mathrm{~mL}$. Sementara untuk titrasi blanko diperoleh volume titrasi yaitu sebesar 0,1 $\mathrm{mL}$. Kadar nitrogen total pada sampel pupuk NPK padat adalah sebesar $10,50 \%$. Hasil pengujian tersebut masih sesuai dengan baku mutu menurut SNI 2803:2010 yaitu batas minimal kadar nitrogen total dalam sampel pupuk NPK padat yaitu $8 \%$.

Unsur nitrogen pada pupuk anorganik NPK sangat dibutuhkan oleh tanaman namun pada takaran yang sesuai. Kelebihan unsur nitrogen mengakibatkan proses pertumbuhan bunga dan buah terhambat, menurunkan kualitas bulir, pertumbuhan vegetatif memanjang (lambat panen). Apabila tanaman kekurangan atau defisiensi unsur nitrogen maka pertumbuhan melambat serta daun menguning atau mengalami klorosis karena nitrogen merupakan unsur dalam molekul klorofil. Unsur nitrogen dalam bentuk amonia dibutuhkan oleh tanah untuk menambah kondisi keasaman atau $\mathrm{pH}$ yang dapat menunjang pertumbuhan tanah.

\section{Penentuan Kadar Air}

Kadar air dalam sampel pupuk ditentukan menggunakan metode destilasi (Aufhauser). Pada penentuan kadar air ini mula-mula sampel pupuk NPK padat dihaluskan agar mendapatkan kadar air yang lebih akurat. Semakin kecil ukuran sampel yang digunakan untuk destilasi, maka semakin besar rendemen air yang akan dihasilkan. Sebanyak $15 \mathrm{~g}$ sampel dimasukkan dalam labu bundar lalu ditambahkan dengan pelarut ksilena sebanyak $30 \mathrm{~mL}$. Penambahan ksilena berfungsi untuk membawa uap air dalam bahan dan secara bersama masuk ke dalam kondensor dan diembunkan kemudian ditampung dalam tabung penampung sehingga terbentuk dua lapisan yaitu air dan ksilena.

Selanjutnya dimasukkan batu didih ke dalam campuran sampel dan ksilena. Hal 
ini bertujuan untuk mencegah terjadinya bumping atau letupan pada saat proses pemanasan dan supaya pemanasan berlangsung merata. Campuran sampel pupuk dan pelarut ksilena dipanaskan untuk menguapkan pelarut bersama-sama dengan air. Pelarut ksilena tergolong senyawa non polar, sedangkan air adalah senyawa polar.

Proses penguapan kedua campuran pelarut akan melewati kondensor dan mengalami kondensasi yaitu perubahan wujud dari gas atau uap menjadi cairan. Kondensasi terjadi pada saat uap didinginkan menjadi cairan (Guenther, 1987). Selanjutnya uap dari campuran pelarut akan mengembun dan masuk ke dalam tabung Aufhauser yang berskala. Pada suhu rendah, air dan ksilena dalam tabung Aufhauser akan kembali terpisah karena kedua pelarut tersebut memiliki kepolaran dan berat jenis yang berbeda. Oleh karena berat jenis air lebih besar daripada pelarut ksilena, maka air berada di bagian bawah pada tabung penampung. Tabung penampung yang dipergunakan saat analisis dilengkapi dengan skala sehingga volume air yang tertampung merupakan volume air yang diperoleh dan digunakan untuk menentukan kadar air dari sampel pupuk NPK padat. Pelarut yang dapat dipergunakan dalam analisa kadar air dengan metode destilasi ini adalah pelarut dengan titik didih yang lebih tinggi dari pada air, dan tidak bercampur dengan air serta mempunyai berat jenis yang lebih rendah dari air seperti toluena, ksilena, benzena, ksilol, dan lain-lain. Dari pengujian yang dilakukan diperoleh volume air sebanyak 0,4 $\mathrm{mL}$ dan kandungan air sebesar $2,67 \%$ sehingga dapat diketahui bahwa kadar air dalam sampel pupuk NPK padat memenuhi standar mutu yaitu maksimal 3\% (b/b).

\section{Penentuan Kadar Pb}

Penentuan kandungan logam timbal (Pb) dalam sampel pupuk NPK padat dilakukan menggunakan spektrofotometer serapan atom (SSA).Langkah awal yaitu preparasi sampel dengan menghaluskan sampel pupuk NPK menggunakan mortar. Tujuan penghalusan ini yaitu untuk membuat luas permukaan lebih besar dan mempermudah sampel larut dalam proses destruksi. Pada penentuam kandungan $\mathrm{Pb}$ ini ada dua tahap yang dilakukan yaitu destruksi sampel dan penentuan cemaran logam $\mathrm{Pb}$ menggunakan spektrofotometer serapan atom.

Proses destruksi sampel menggunakan campuran asam pekat yaitu asam klorida dan asam nitrat. Destruksi sampel ini bertujuan untuk menghilangkan senyawasenyawa yang tidak diperlukan dalam sampel, melarutkan logam timbal dalam sampel pupuk NPK dan agar sampel mudah larut. Destruksi menggunakan asam kuat agar logam timbal dapat terpisah dari sampel, dan dilakukan pemanasan untuk mendapatkan hasil analisis yang maksimal. Sampel hasil destruksi kemudian disaring menggunakan kertas saring whatman 41 untuk memisahkan filtrat dan residu agar larutan ekstrak bisa dianalisis menggunakan spektrofotometer serapan atom.

Pengukuran logam dengan spektrofotometer serapan atom yang pertama kali dilakukan adalah optimasi alat, pengukuran larutan standar $\mathrm{Pb}$, dan pengukuran larutan sampel. Pengukuran larutan standar timbal diukur absorbansinya pada panjang gelombang 283,3 nm. Hasil pengukuran absorbansi larutan standar $\mathrm{Pb}$ ditunjukkan pada Gambar 5.

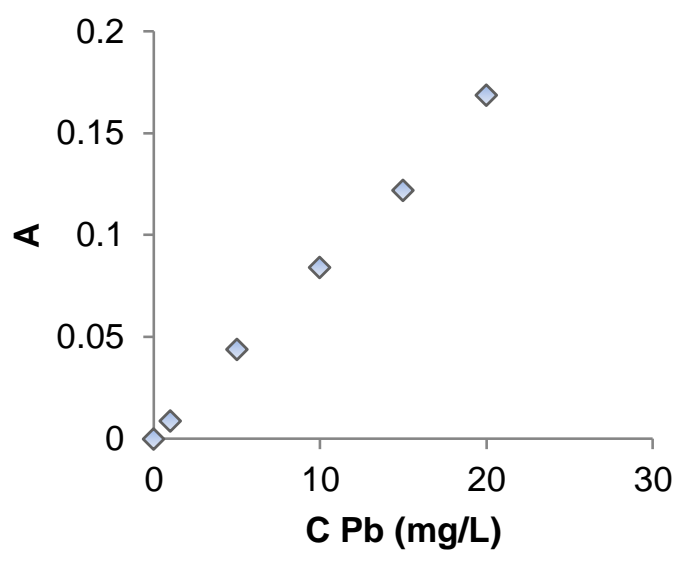

Gambar 5. Kurva larutan standar $\mathrm{Pb}$

Untuk memperoleh kadar logam timbal pada sampel pupuk anorganik NPK padat digunakan rumus pada persamaan 2 .

$$
\begin{aligned}
& \text { kadar } \mathrm{Pb}\left(\frac{\mathrm{mg}}{\mathrm{kg}}\right)=\frac{\mathrm{C} \times \mathrm{P} \times \mathrm{V}}{\mathrm{W}} \\
& \text { Keterangan: } \quad \mathrm{C}=\text { konsentrasi } \mathrm{Pb}(\mathrm{mg} / \mathrm{L}) \\
& \mathrm{P}=\text { faktor pengenceran } \\
& \mathrm{V}=\text { volume }(\mathrm{mL}) \\
& \mathrm{W}=\text { berat sampel }(\mathrm{g})
\end{aligned}
$$


hasil pensentrasi logam $\mathrm{Pb}$ dalam sampel diperoleh sebesar $0,481 \mathrm{mg} / \mathrm{L}$. sehingga kadar $\mathrm{Pb}$ yang diperoleh sebesar 16,03 $\mathrm{mg} / \mathrm{kg}$. Dari hasil yang didapat dapat diketahui bahwa kadar $\mathrm{Pb}$ yang diperoleh memenuhi syarat mutu berdasarkan SNI 2803:2010 yaitu maksimal 500 mg/kg.

Logam $\mathrm{Pb}$ sebagian besar diakumulasikan oleh tanaman pada bagian batang, daun dan akar. Proses sirkulasi logam $\mathrm{Pb}$ dari tanah ke tanaman sangat tergantung pada komposisi dan $\mathrm{pH}$ tanah. Proses fotosintesis dan pertumbuhan pada tanaman akan terganggu apabila tanah terpapar konsentrasi timbal yang tinggi yaitu 100-1000 mg/kg (Charlene, 2004). Logam timbal dapat diserap oleh tanaman saat kondisi kesuburan serta kandungan bahan organik tanah sangat rendah sehingga logam timbal dapat terlepas pada larutan tanah. Logam timbal pada pupuk anorganik NPK padat berikatan dengan unsur hara mikro seperti ion nitrat membentuk timbal nitrat atau $\left[\mathrm{Pb}\left(\mathrm{NO}_{3}\right)_{2}\right]$ yang mengindikasikan bahwa logam timbal di dalam tanah selalu terikat kuat pada bahan organik atau koloid yang terpresipitasi.

\section{SIMPULAN}

Kesimpulan yang diperoleh dari penentuan nitrogen total, kadar air, dan kandungan cemaran logam $\mathrm{Pb}$ dalam sampel pupuk anorganik NPK padat adalah kandungan nitrogen total $10,50 \%$, kadar air 2,67\%, kandungan cemaran logam $\mathrm{Pb} 16,03$ $\mathrm{mg} / \mathrm{kg}$. Kandungan nitrogen total, kadar air dan cemaran logam $\mathrm{Pb}$ dalam sampel pupuk anorganik NPK padat memenuhi persyaratan baku mutu SNI 2803:2010.

\section{SARAN}

Berdasarkan hasil pengujian yang diperoleh saran yang dapat diberikan yaitu penentuan kadar air dapat menggunakan metode yang lain seperti Karl Fischer dan gravimetri. Selain itu perlu pengujian kadar fosfor, kalium dan logam berat yang lain sebagai bagian dari kualitas pupuk anorganik NPK padat.

\section{UCAPAN TERIMAKASIH}

Ucapan terimakasih disampaikan kepada Denda Fitria Hidayah atas bantuannya di laboratorium.Selain juga kepada laboratorium kimia terapan DIII Analis Kimia FMIPA UII dan laboratorium terpadu UII untuk fasilitas pengujian.

\section{DAFTAR PUSTKA}

Agustina, L., 1990, Dasar Nutrisi Tanaman. Jakarta: Rineka Cipta.

Andarwulan, N., Kusnandar, F., dan Herawati, D., 2011, Analisa Pangan, Jakarta: Penerbit Dian Rakyat.

Achorn, F. P., dan Balay, 1997, Produksi, Pemasaran, dan Penggunaan Pupuk-pupuk Padat, Larutan, dan Suspensi dalam Teknologi dan Penggunaan Pupuk, Edisi ketiga. Penerjemah D.H Gunadi. Yogyakarta: Gajah Mada University Press Hal 724-751.

Buckman, H. O., dan Brady, 1982, IImu Tanah. Bharata Karya Aksara: Jakarta.

Buckle, K A, Edward, R.A., Fleet, G.H., dan Wootton, M., 2008, Food Science, Penerjemah Hari Purnomo dan Adiono dalam IImu Pangan Universitas Indonesia: Jakarta.

BSN, 2010, SNI 2803:2010 Pupuk NPK Padat, Badan Standardisasi Nasional, Jakarta.

Charlene., 2004, Pencemaran Logam Berat Timbal(Pb) dan Cadmium (Cd) pada Sayur-Sayuran. Falsafah Sains. IPB: Bogor.

Chorn, A., dan Ta'minuddin, 1978, Penuntun Praktikum Khusus.Sekolah Analis Kimia Menengah Bogor: Pusat Pendidikan dan Latihan. Departemen Perindustrian.

Damanik, M. B., 2011, Kesuburan Tanah dan Pemupukan. Medan: USU Press.

Darmono., 1995, Logam dalam Sistem Biologi Makhluk Hidup. Jakarta: UI Press.

Day, R. A dan Underwood., 2002, Analisis Kuantitatif diterjemahkan oleh Lis Sopyan, Edisi Ke Enam. Jakarta: Erlangga.

Day, R. A dan Underwood., 1989, Analisis Kimia Kuantitaif Edisi keenam. Jakarta: Erlangga. 
Elfiati, D., 2005, Peranan Mikroba Pelarut Fosfat Terhadap Pertumbuhan Tanaman. USU e-repository: Medan

Fifield, F. W., 1983, Principle and Practice Of Analytical Chemistry, Edisi Ke Dua, London: International Textbook Company Limited.

Guenther, E., 1987, Minyak Atsiri I, diterjemahkan S. Ketaren, Jilid I, Penerbit UI Press, Jakarta.

Hadisuwito, S., 2012, Membuat Pupuk Organik Cair, Jakarta: PT Agromedia Pustaka.

Hardjowigeno, S. 2003, Ilmu Tanah, Jakarta: Akademiko Pressindo.

Hasibuan, B., 2006, Pupuk dan Pemupukan, Medan: USU Press.

Khopkar, S., 2007, Konsep Dasar Analitik, Jakarta: UI Press.

Khopkar, S.,1990, Konsep Dasar Kimia Analitik. Jakarta: UI Press.

Lindawati, N., Izhar, dan Syafira, H., 2000, Pengaruh Pemupukan Nitrogen dan Interval Pemotongan Terhadap Produktivitas dan Kualitas Rumput Lokal Kumpai pada Tanah Podzolik Merah Kuning, JPPTP 2(2):130-133

Lingga, P. D., dan Marsono, 2000, Petunjuk Penggunaan Pupuk, Jakarta: Penebar Swadaya.

Madjid, A., 2009, Dasar-Dasar IImu Tanah.Unsri : Malang.

Makiyah, M., 2001, Penentuan Kadar N, P dan K pada Pupuk Cair Limbah Tahu dengan Penambahan Tanaman Matahari Meksiko (Thitonia Diversivolia), Skripsi. Kimia FMIPA Universitas Negeri Semarang: Semarang.

Mulja, M. D., 1995, Analisis Instrumental. Surabaya: Airlangga University Press.

Nielsen, S.S., 2003, Food Analysis $3^{\text {rd }}$ edition, Kluwer Academic, New York.

Novizan, 2002, Petunjuk Pemupukan yang Efektif. Agromedia Pustaka. Jakarta: Hal: 23-24

Palar, H., 1994, Pencemaran dan Toksikologi Logam Berat. Jakarta: Rineka Cipta.

Raimon, 1993, Perbandingan Metoda Destruksi Basah dan Kering Secara Spektrofotometri Serapan Atom, Lokakarya Nasional, Jaringan
Kerjasama Kimia Analitik Indonesia, Yogyakarta.

Rauf, A. W., 2000, Peranan Pupuk NPK pada Tanaman Padi. Irian Jaya: Departemen Pertanian (Badan Penelitian dan Pengembangan Pertanian).

Rinsema, W.T., 1993, Pupuk dan Cara Pemupukan, Jakarta: Bharata Cipta.

Rohman, A., 2007, Kimia Farmasi Analisis, Yogyakarta: Pustaka Pelajar.

Santoso, B.B., 2010, Faktor-Faktor Pertumbuhan dan Penggolongan Tanaman Hias. Fakultas Pertanian, Universitas Gajah Mada, Yogyakarta.

Saribun, D.S., 2008, Pengaruh Pupuk Majemuk NPK pada Berbagai Dosis terhadap $\mathrm{pH}, \mathrm{P}$ - $\quad$ Potensial dan P-Tersedia serta Hasil CAYSIN (Brassicia juncea) pada Fluventic Eutrudepts Jatinangor. Skripsi, Fakultas Pertanian UNPAD, Jatinangor.

Sastrohamidjojo, H., 1991, Spektroskopi, Edisi Kedua, Liberty: Yogyakarta.

Simpson, K., 1986, Fertilizer and Manures, Longman Group Limited: New York.

Skoog, D., West, D.M., dan Holler, F.J., 2000.Fundamentals of Analytical Chemistry. Brooks/Cole Publishing Company, USA.

Sudarmadji, S., Haryono, B., dan Suhardi., 2003, Analisa Bahan Makanan dan Pertanian (edisi kedua). Yogyakarta: Penerbit Liberty.

Sumadinata, C.K., 1997, Penggunaan Kotoran Sapi, Dolomit dan Zeolit Pada Oxyc Dystropepts Darmaga yang diberi Perlakuan Logam Berat pada Taraf Meracun dan Pengaruhnya terhadap Pertumbuhan Vegetatif Jagung. Skripsi, Fakultas Pertanian, IPB Bogor.

Sumardi, 1981, Metode Destruksi Contoh Secara Kering Dalam Analisa UnsurUnsur Fe-Cu-Mn dan Zn Dalam Contoh-Contoh Biologis, Prosiding Seminar Nasional Metode Analisis, Lembaga Kimia Nasional. Jakarta: LIPI.

Suriadikarta, D. A., 2006, Pupuk Organik dan Pupuk Hayati, Organic Fertilizer and Biofertilizer. Balai Besar Litbang 
sumber Daya Lahan Pertanian, Badan Penelitian dan Pengembangan Pertanian:Bogor.

Sutejo, M., 2002, Pupuk dan Cara Pemupukan. Rineka Cipta: Jakarta.

Syukur, A., Harsono E.S. \&Sulakhudin., 2007, Pengaruh Pemberian Pupuk Kandang dan NPK Terhadap Beberapa Sifat Kimia dan Fisika Pasir Pantai Samas Bantul. Jurnal Tanah dan Air, 8(1), 35-44.

Svehla., 1990, Analisis Anorganik Kualitatif Makro dan Semimikro. Jakarta: PT Kalman Media Pustaka.

Svehla., 1979, Buku Ajar Kimia Analisis Kuantitatif Anorganik, diterjemahkan oleh H. Pudjaatmaka dan Setiono. Jakarta: Buku Kedokteran EGC.

Tan, K. H., 1996, Soil Sampling, Preparation and Analysis, New York: Penerbit Marcel Dekker, Inc.
Widiyandari., 2006, Penetapan Kadar Nitrogen yang Terkandung dalam Pupuk Nitrogen, Phospor, Kalium (NPK) di PT Rispa Medan. Medan: Karya IImiah Universitas Sumatera Utara.

Widodo, A. H., 2007, Perbandingan Penggunaan Pupuk Organik dan Anorganik Terhadap Sifat Kimia Tanah Sawah di Desa Segaran Kecamatan Dlanggu Kabupaten Klaten, Jurnal Tanah dan Air Vol 8(1), 56-65.

Winarno, F.G., 2002, Kimia Pangan dan Gizi, PT Gramedia Pustaka Utama, Jakarta.

Wiryanta, B., 2008, Budidaya Cabai Merah pada Musim Hujan, Agro Media Pustaka: Jakarta.

Yuwono., 2004,(Rinsema, 1993). Yogyakarta: Penerbit UGM Press. 